\title{
Decrease of Gray Matter Volume in the Midbrain is Associated with Treatment Response in Medication-Overuse Headache: Possible Influence of Orbitofrontal Cortex
}

\author{
Franz Riederer, ${ }^{1}$ Andreas R. Gantenbein, ${ }^{1}$ Marvin Marti, ${ }^{1}$ Roger Luechinger, ${ }^{2}$ Spyridon Kollias, ${ }^{3}$ and Peter S. Sándor ${ }^{1,4}$ \\ ${ }^{1}$ Department of Neurology, University Hospital Zurich, CH-8091 Zurich, Switzerland, ${ }^{2}$ Institute for Biomedical Engineering, Swiss Federal Institute of \\ Technology and the University of Zurich, CH-8091 Zurich, Switzerland, ${ }^{3}$ Institute of Neuroradiology, University Hospital Zurich, CH-8091 Zurich, \\ Switzerland, and ${ }^{4}$ Rehaclinic Bad Zurzach, CH-5330 Bad Zurzach, Switzerland
}

Patients with chronic daily headache and overuse of analgesics, triptans, or other acute headache compounds, are considered to suffer from medication-overuse headache (MOH). This implies that medication overuse is the cause of headache chronification. It remains a key question why only two-thirds of patients with chronic migraine-like headache and overuse of pain medication improve after detoxification, whereas the remainder continue to have chronic headache. In the present longitudinal MRI study, we used voxel-based morphometry to investigate gray matter changes related to medication withdrawal in a group of humans with $\mathrm{MOH}$. As a main result, we found that only patients with significant clinical improvement showed a significant decrease of previously increased gray matter in the midbrain including periaqueductal gray matter and nucleus cuneiformis, whereas patients without improvement did not. Patients without treatment response had less gray matter in the orbitofrontal cortex. Another striking result is the correlation of treatment response with the amount of orbitofrontal gray matter. Thus, we demonstrate adaptive gray matter changes within the pain modulatory system in patients with $\mathrm{MOH}$ who responded to detoxification, probably reflecting neuronal plasticity. Decreased gray matter in the orbitofrontal cortex at baseline may be predictive of poor response to treatment.

\section{Introduction}

Medication-overuse headache $(\mathrm{MOH})$ is a complication of migraine that causes significant social and financial burden. $\mathrm{MOH}$ is defined as headache for $\geq 15$ days per month that develops, or significantly worsens, during medication overuse (Headache Classification Subcommittee of the International Headache Society, 2004; Olesen et al., 2006). According to the diagnostic criteria of the Headache Classification Subcommittee of the International Headache Society (2004), MOH could only be diagnosed if chronic headache returned to its episodic pattern after the cessation of medication overuse. Thus, the diagnosis of $\mathrm{MOH}$ could only be made retrospectively. In 2006, a broader definition of $\mathrm{MOH}$ was proposed (Olesen et al., 2006) in which the improvement after withdrawal was no longer mandatory, thus allowing for a prospective diagnosis.

Recent studies demonstrated metabolic and structural abnormalities in $\mathrm{MOH}$ (Fumal et al., 2006; Riederer et al., 2012). In a

\footnotetext{
Received Aug. 9, 2012; revised July 11, 2013; accepted July 12, 2013.

Author contributions: F.R. and P.S.S. designed research; F.R., A.R.G., M.M., and R.L. performed research; R.L. and S.K. contributed unpublished reagents/analytic tools; F.R. and M.M. analyzed data; F.R., S.K., and P.S.S. wrote the paper.

This work was supported by the Werner Alfred Selo Stiftung and the Schweizerische Nationalfonds zur Förderung der Wissenschaftlichen Forschung, project no. 3200030_127606/1 (P.S.S.)

The authors declare no competing financial interests.

Correspondence should be addressed to Peter S. Sándor, Rehaclinic Bad Zurzach, Quellenstrasse 34, CH-5330 Bad Zurzach, Switzerland. E-mail: peter.sandor@ksb.ch.

DOI:10.1523/JNEUROSCI.3804-12.2013

Copyright $\odot 2013$ the authors $\quad 0270-6474 / 13 / 3315343-07 \$ 15.00 / 0$
}

PET study, persistent hypometabolism was found in orbitofrontal cortex (OFC), whereas other dysmetabolic regions returned to normal after withdrawal (Fumal et al., 2006). Since hypofunction of the OFC is known to occur in drug dependence, it was suggested that this may predispose subgroups of persons who experience migraine headaches to recurrent medication overuse (Fumal et al., 2006). Voxel-based morphometry (VBM) is a powerful tool with which to study neurological disease, with the detection of structural changes in the brain being operator independent (Ashburner and Friston, 2000; Whitwell, 2009). In a VBM study, we found gray matter (GM) changes in structures related to pain processing and antinociception (Riederer et al., 2012). Specifically, GM increases were found in the periaqueductal gray of the midbrain (PAG), the thalamus, and the striatum, and decreases were found in frontal regions, including OFC and the insula.

The PAG is a substantial component of the descending pain modulatory network and exerts an inhibitory or excitatory control on nociceptive transmission via the rostral ventromedial medulla (RVM), which in turn projects to the spinal and medullary dorsal horn (Heinricher et al., 2009; Benarroch, 2012). While it is widely accepted that that the brainstem plays a pivotal role in migraine pathophysiology (Raskin et al., 1987; Weiller et al., 1995; Veloso et al., 1998; Welch et al., 2001; Afridi et al., 2005), dysfunction of descending pain modulatory systems with a shift toward pain facilitation has recently been suggested in MOH (Perrotta et al., 2010, 2012). Importantly, abnormal processing of pain stimuli and impaired su- 
praspinal pain control in patients with $\mathrm{MOH}$ improved after detoxification.

Here we investigated whether the GM changes associated with $\mathrm{MOH}$ in humans, such as increase in the midbrain, thalamus, and striatum, and decrease in frontal regions (Riederer et al., 2012), were reversible after detoxification. Assuming that VBM detects neuroplasticity in adults (Draganski et al., 2004; May, 2011), we hypothesized neuroplastic changes particularly in brainstem and frontal cortex in patients with significant clinical improvement (responders), but not in the patients without improvement (nonresponders).

Further, we investigated whether regional GM changes at baseline would distinguish between responders and nonresponders, and thus predict treatment response, focusing on OFC. To test these hypotheses, high-resolution structural MRIs were performed in $\mathrm{MOH}$ patients before and after detoxification.

\section{Materials and Methods}

This is an extension of a previously published study (Riederer et al., 2012). The study was approved by the ethics committee of the Canton Zurich. Written informed consent was obtained from all study participants according to the Declaration of Helsinki.

Subjects. Thirty-eight patients with $\mathrm{MOH}$, according to the proposed revision of criteria of the Headache Classification Subcommittee of the International Headache Society (2004) by Olesen (Olesen et al., 2006), were included in the study. Medication overuse was defined as treatment with the following acute/symptomatic treatment drugs: ergotamine, triptans, opioids, or combination analgesic medications $\geq 10 \mathrm{~d} /$ month; or simple analgesics or any combination of ergotamine, triptans, or analgesics opioids without overuse of any single class alone $\geq 15 \mathrm{~d} /$ month (Headache Classification Subcommittee of the International Headache Society, 2004; Olesen et al., 2006) on a regular basis for $\geq 3$ months.

Headache days per month and days with pain medication per month were recorded during a baseline period at least 1 month before scan 1 and in the month before scan 2, which was scheduled at least 3 months after scan 1, based on headache diaries. Patients were considered as responders if they had a reduction of $\geq 50 \%$ in headache days per month at followup. Each responder was age and gender matched to a corresponding nonresponder. Patients with known abnormalities in brain imaging (MRI or CT scans) were not included.

Structural MRI. High-resolution structural MRI was performed in all patients before medication withdrawal and 3 months after. All MRI data were obtained on a 3 tesla Philips Achieva scanner (Philips Medical Systems) at the Institute for Biomedical Engineering, Swiss Federal Institute of Technology and University of Zurich. The T1-weighted volume sequences of the whole brain were acquired using a three-dimensional magnetization-prepared rapid acquisition gradient echo sequence (TR, $8.7 \mathrm{~ms}$; TE, $2.3 \mathrm{~ms}$; flip angle, $8.0^{\circ}$; voxel size, $0.86 \times 0.86 \times 1.0 \mathrm{~mm}$; axial slice orientation, matrix size $256 \times 256$ ).

Voxel-based morphometry. Images were analyzed with the VBM8 toolbox (http://dbm.neuro.uni-jena.de/vbm/), incorporated in the SPM8 software running on MATLAB R2008b (MathWorks). The longitudinal preprocessing approach integrated into the VBM8 toolbox was used (Bezzola et al., 2011). In brief, the following steps were performed: (1) registration of time point 2 scan to time point 1 scan for each subject separately; (2) intrasubject bias correction; (3) segmentation into different tissue classes; (4) linear and nonlinear registration; and (5) modulation of tissue segments by the nonlinear normalization parameters to account for individual brain size differences. The normalized GM segments were smoothed using a $6 \mathrm{~mm}$ FWHM Gaussian kernel.

Statistical analysis. Clinical data were analyzed with IBM SPSS Statistics 20 program. Student's $t$ tests were used to compare parametric data and Mann-Whitney $U$ tests for nonparametric data.

Imaging data were analyzed with SPM8 (http://www.fil.ion.ucl.ac. $\mathrm{uk} / \mathrm{spm} / \mathrm{software} / \mathrm{spm} 8 /$ ). First, baseline and follow-up scans were compared in responders and nonresponders matched for age and sex, using a repeated-measures ANOVA (flexible-factorial) model with within-
Table 1. Demographic and clinical data in patients with $\mathrm{MOH}$

\begin{tabular}{lccc}
\hline & $\begin{array}{l}\text { Responders } \\
(N=11)\end{array}$ & $\begin{array}{l}\text { Nonresponders } \\
(N=11)\end{array}$ & $p$ value $^{a}$ \\
\hline Time between scans (d) & $113.2 \pm 42.6$ & $107.3 \pm 32.3$ & $0.720(t$ test $)$ \\
Age (years) & $41.8 \pm 9.1$ & $44.3 \pm 12.0$ & 0.365 \\
Gender (female/male) & $9 / 2$ & $9 / 2$ & $N A$ \\
Headache & & & \\
$\quad$ d/month at baseline & $25.0 \pm 6.8$ & $26.2 \pm 5.3$ & 0.652 \\
$\quad$ \% reduction & $73.4 \pm 10.1$ & $18.7 \pm 27.5$ & $<0.001$ \\
Receiving medication & & & \\
$\quad$ d/month at follow-up & $6.4 \pm 4.9$ & $12.8 \pm 9.4$ & 0.047 \\
$\quad \Delta$ d/month at follow-up & $-14.2 \pm 8.7$ & $-10.4 \pm 10.8$ & 0.300 \\
Headache duration (years) & $20.1 \pm 12.2$ & $19.0 \pm 10.0$ & 1.000 \\
HADS-A (baseline) & $8.5 \pm 4.2$ & $8.3 \pm 3.6$ & 0.898 \\
HADS-D (baseline) & $7.9 \pm 6.3$ & $6.9 \pm 5.0$ & 0.699 \\
\hline
\end{tabular}

HADS, Hospital Anxiety and Depression Scale; HADS-A, anxiety subscale; HADS-D, depression subscale; NA, no applicable.

${ }^{a}$ Mann-Whitney $U$ test, unless otherwise indicated.

subject factor time $(\mathrm{T} 1, \mathrm{~T} 2)$ and between-subjects factor group (responders, nonresponders), testing for a group $\times$ time interaction. T-contrasts were defined to identify regions with significant GM decrease or increase from scan 1 to scan 2 in responders and nonresponders, respectively. The resulting set of voxels for each contrast was thresholded at $p<0.05$, corrected for multiple comparisons with familywise error. For predefined regions (midbrain, thalamus, insula, striatum, OFC, and prefrontal cortex), a region of interest (ROI) analysis was performed, using WFU-PickAtlas (at $p<0.05$, corrected).

Subsequently, baseline scans of responders and matched nonresponders were compared using a two-sample $t$ test model. Total GM volume was used as nuisance variable. Here, SPM small-volume correction (sphere with a radius of $10 \mathrm{~mm}$, at $p<0.05$ ) within the predefined ROIs was used. For all analyses, an extent threshold of a minimum of 5 voxels was used. All coordinates are given in Montreal Neurological Institute (MNI) space. In the significant cluster in the OFC cortex that resulted from baseline comparisons, individual GM volumes of all patients were extracted using the marsbar toolbox and correlated with treatment response (defined as the percentage reduction in headache days at follow-up) within SPSS.

Possible correlation of cerebral GM at baseline with intake of acute medication (days with pain medication per month) were investigated in a multiple regression model within SPM8, including total GM volume, age, and gender as nuisance variables. Whole-brain and ROI analyses using WFU-PickAtlas (at $p<0.05$, corrected) were performed.

\section{Results}

\section{Clinical data}

Four patients were lost during follow-up, and three patients (two classified as responders, one as a nonresponder) refused to undergo the second MRI scan. Complete clinical and imaging datasets could be obtained from 31 patients (17 responders, 14 nonresponders). Results from this group were similar to those in the present study and have been published in abstract form (Riederer et al., 2013). Eleven responders ( 9 females, 2 males) could be age and gender matched to 11 nonresponders ( 9 females, 2 males). Demographic and clinical data of this group are summarized in Table 1. Baseline characteristics did not differ significantly between responders and nonresponders. At follow-up, responders had significantly more reduction in number of headache days and significantly fewer days on pain medication than nonresponders. Most patients overused triptans and/or simple analgesics. All medications, including prophylactic medications, are listed in Table 2.

\section{Follow-up 12 months after detoxification}

Electronic charts were available from all patients. Twelve months after detoxification data were available for 10 responders and 8 
Table 2. Medication in patients with medication-overuse headache

\begin{tabular}{|c|c|c|c|c|c|c|c|}
\hline \multirow[b]{2}{*}{ Patient No. } & \multirow[b]{2}{*}{ Responder } & \multirow[b]{2}{*}{ Sex } & \multirow[b]{2}{*}{ Age (years) } & \multicolumn{2}{|l|}{ Prophylactic medications } & \multirow[b]{2}{*}{ Acute headache medication } & \multirow[b]{2}{*}{ Contraceptives } \\
\hline & & & & MRI 1 & MRI 2 & & \\
\hline 1 & Yes & M & 43 & Topiramate, duloxetine & Duloxetine & Triptans, SA & - \\
\hline 2 & Yes & $\mathrm{F}$ & 46 & Pregabalin, trimipramine, venlafaxine & Pregabalin, trimipramine, venlafaxine & SA & - \\
\hline 3 & Yes & $\mathrm{F}$ & 26 & - & Magnesium, riboflavin & SA & IUD (gestagen) \\
\hline 4 & Yes & $\mathrm{F}$ & 23 & Magnesium, riboflavin, topiramate, $\beta$ blockers & - & Triptans, SA & - \\
\hline 5 & Yes & $\mathrm{F}$ & 41 & Valproate, magnesium & Riboflavin, candesartan & Triptans, SA & - \\
\hline 6 & Yes & $\mathrm{F}$ & 42 & Lamotrigine & Topiramate & Triptans, CA & - \\
\hline 7 & Yes & M & 50 & Venlafaxine & Venlafaxine, lamotrigine, trazodone & Triptans, SA & - \\
\hline 8 & Yes & $\mathrm{F}$ & 46 & - & Venlafaxine & Triptans & Oral contraceptive \\
\hline 9 & Yes & $\mathrm{F}$ & 48 & - & - & Triptans & - \\
\hline 10 & Yes & $\mathrm{F}$ & 51 & Magnesium & Magnesium, metoprolol & SA & - \\
\hline 11 & Yes & $\mathrm{F}$ & 44 & - & Valproate & Triptans & - \\
\hline 12 & No & M & 50 & Valproate, mirtazapine, riboflavin & Trazodone, duloxetine & Triptans, SA & - \\
\hline 13 & No & $\mathrm{F}$ & 42 & Magnesium & Metoprolol & Triptans, SA & Vaginal ring \\
\hline 14 & No & $\mathrm{F}$ & 23 & - & Venlafaxine, riboflavin, magnesium & SA & Oral contraceptive \\
\hline 15 & No & $\mathrm{F}$ & 53 & - & - & Triptans &.- \\
\hline 16 & No & $\mathrm{F}$ & 45 & Riboflavin, magnesium & Venlafaxine, magnesium & Triptans & - \\
\hline 17 & No & $\mathrm{F}$ & 56 & - & Topiramate & Triptans, SA & - \\
\hline 18 & No & $\mathrm{F}$ & 45 & Topiramate & Topiramate & SA & - \\
\hline 19 & No & $\mathrm{F}$ & 54 & Magnesium, riboflavin, pregabalin & - & Triptans & - \\
\hline 20 & No & $\mathrm{F}$ & 21 & Magnesium & Topiramate & SA & - \\
\hline 21 & No & M & 44 & Citalopram & Riboflavin & SA, triptans & - \\
\hline 22 & No & $\mathrm{F}$ & 54 & Mirtazapin & Mirtazapin, venlafaxine, magnesium & SA & - \\
\hline
\end{tabular}

$C A$, Combination analgesics; IUD, intrauterine device; $S A$, simple analgesics; $M$, male; $F$, female.

nonresponders. Two responders had relapsed to $\mathrm{MOH}$ after 12 months. Nonresponders continued to have chronic headaches.

\section{Imaging data}

In responders, $\mathrm{GM}$ in the midbrain $(x=-5, y=-34, z=-8$; $\mathrm{T}=6.12, p=0.006$, ROI corrected; cluster size, $k=21$ voxels) decreased significantly after medication withdrawal (Fig. 1). In contrast, in nonresponders the GM between scans 1 and 2 was not significantly different. In all patients, GM in the significant midbrain cluster (Fig. 1) was extracted for scans 1 and 2. The difference in extracted GM between scans 1 and 2 correlated positively with treatment response (Spearman's $\rho=0.500, p=0.018$; corrected for age: $\rho=0.551, p=0.010$; i.e., greater GM reduction was associated with greater treatment response). The difference in extracted GM in the midbrain did not correlate with the reduction of days per month with acute medication intake (Spearman's $\rho=0.161, p=0.473$ ). No other regions showed significant GM decreases in responders and nonresponders.

Then, we defined T-contrasts to identify regions where GM would increase significantly from scan 1 to scan 2 . No significant clusters were identified in responders or nonresponders.

Subsequently, we defined T-contrasts to identify GM increases or decreases between responders and nonresponders at baseline. Nonresponders had significantly less GM in the right OFC $(x=8, y=32, z=-26 ; \mathrm{T}=5.43, p=0.012$, SVC corrected; cluster size, $k=26$ voxels). Extracted GM in this cluster correlated positively with treatment response (Spearman's $\rho=0.687$, $p<0.001$; Fig. 2). This correlation persisted when corrected for age (Spearman's $\rho=0.618, p=0.003$ ).

No significant correlation between GM at baseline and days with pain medication per month were found.

\section{Discussion}

In this study, we investigated whether GM changes related to $\mathrm{MOH}$ such as increased GM in the midbrain and decreased GM in frontal regions are reversible after detoxification. The main finding was that GM in the midbrain, which had been found to be increased compared with healthy controls in a previous study
(Riederer et al., 2012), significantly decreased only in patients who responded to treatment (i.e., those who had at least a 50\% reduction in number of headache days). Nonresponders showed no significant changes between scans 1 and 2. The magnitude of GM reduction correlated positively with treatment response. In addition, we found that nonresponders had less GM in the OFC at baseline and a positive correlation of GM in this region with response to treatment (i.e., more GM at baseline was associated with a greater reduction of headache days at follow-up).

We suggest that a decrease of GM in the midbrain may indicate neuronal plasticity related to restitution of a facilitatory/ inhibitory balance within the descending pain-modulating systems.

Brainstem dysfunction has been suggested in migraine ( $\mathrm{Pi}$ etrobon and Striessnig, 2003). It has been observed that electrical stimulation for pain other than headache (Raskin et al., 1987; Veloso et al., 1998) or lesions in the PAG (Haas et al., 1993; Goadsby, 2002) can cause migraine-like headaches in previously migraine-free subjects. Structural abnormalities include increased GM in migraine (Rocca et al., 2006) and progressive perturbation of iron homeostasis in episodic and chronic migraine (Welch et al., 2001). Functional neuroimaging studies reported increased metabolism in the brainstem during spontaneous migraine attacks (Weiller et al., 1995; Afridi et al., 2005). Areas of increased metabolism probably included the dorsal raphe nucleus (DRN) located ventrally to the PAG and the locus ceruleus (Weiller et al., 1995).

Based on Duvernoy's Atlas of the Human Brain Stem and Cerebellum (Naidich et al., 2009), the longitudinal GM decreases observed in our study included the PAG, adjacent midbrain reticular formation with nucleus cuneiformis (NCF), and the DRN.

The PAG has a major role in integrated behavioral responses of an individual to pain or external stimuli such as threat, coordinating specific patterns of cardiovascular, motor, and pain modulatory responses, according to the type of stress and the individual's perception to support active (e.g., fight or flight) or passive coping strategies (Benarroch, 2012). The PAG consists of 
A
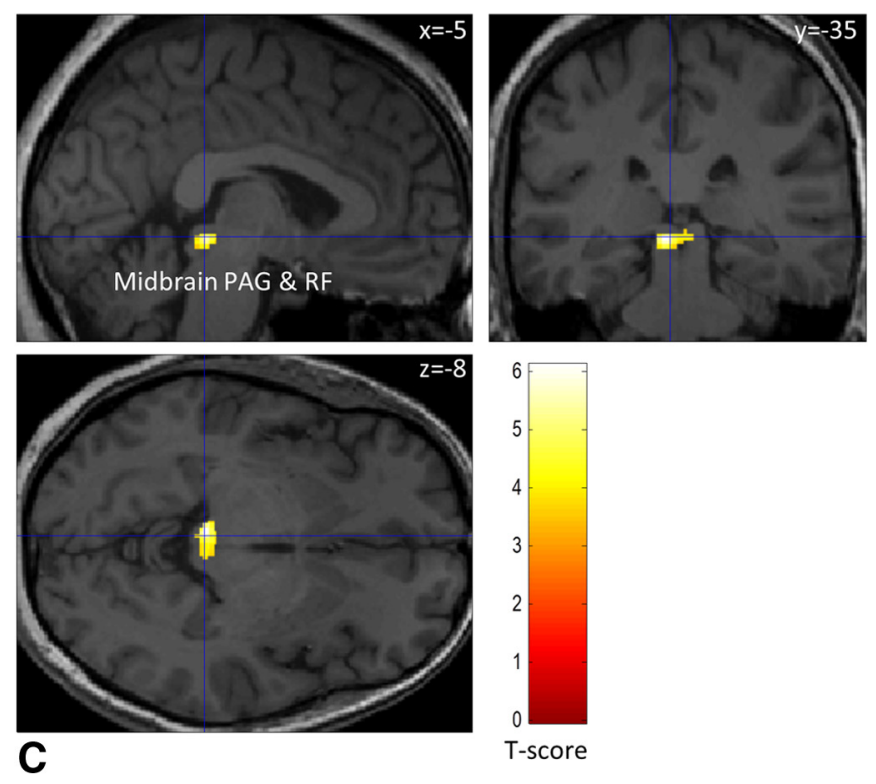

T-score

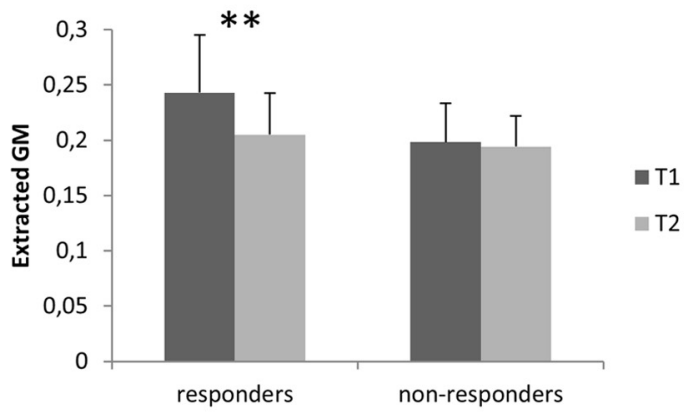

B

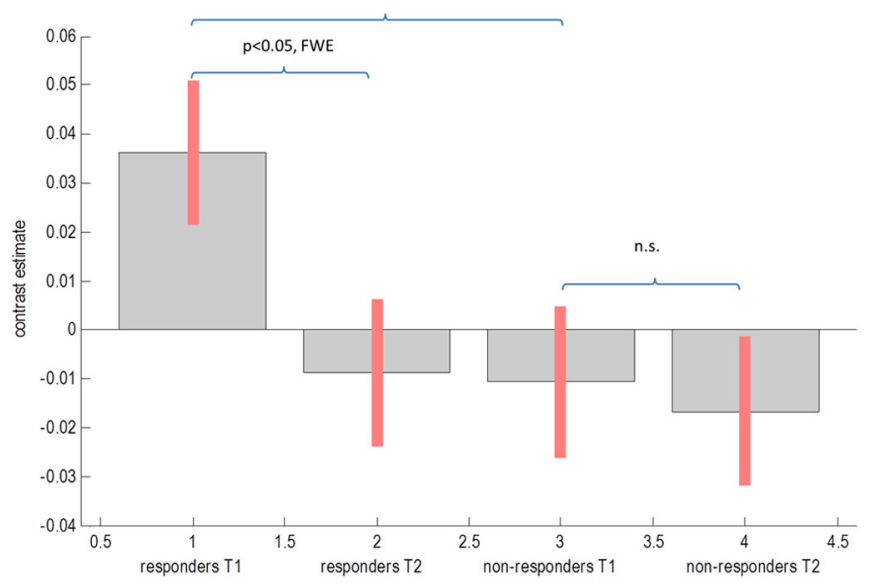

D

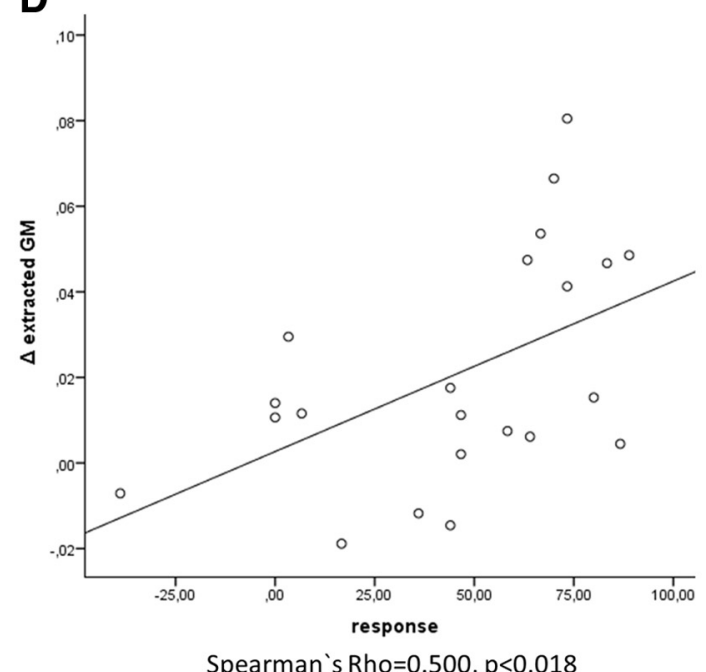

Figure 1. A, Voxels with significant GM decrease in responders after detoxification projected on an MRI of a patient with MOH. Voxels include the PAG and midbrain reticular formation (RF). The right side in the coronal section and the lower side in the axial section correspond to the right patient side. For display, results were thresholded at $p<0.001$, uncorrected. Slice locations are given in MNI space. $\boldsymbol{B}$, Plots of effect size (parameter $\beta$ estimates in centered arbitrary units, $90 \% \mathrm{Cl}$ ) from SPM analyses in the global maximum. The $x$-axis indicates time points of MRI scans for responders ( $\mathrm{T} 1$, before detoxification; $\mathrm{T} 2$, after detoxification). Only responders show a significant $\mathrm{GM}$ decrease in the midbrain from scan 1 to scan 2 [repeated-measures ANOVA, $p<0.05$, corrected for multiple comparisons with familywise error (FWE) across the ROI]. Exploratory analyses showed that responders had more GM in the midbrain at baseline compared with nonresponders (two-sample $t$ test, $p<0.005$, uncorrected). C, GM volumes in the significant cluster from $\boldsymbol{A}$ extracted from individual scans. ${ }^{* *} p<0.001$, paired $t$ test. $\boldsymbol{D}$, The magnitude of gray matter volume reduction correlates with reduction in the number of headache days per month in percentage from baseline (Spearman's $\rho=0.500, p<0.018$ ).

distinct longitudinal columns that receive selective afferents from the forebrain including, OFC regions, brainstem, and sensory neurons from the dorsal horn and trigeminal nuclei (Behbehani, 1995; Benarroch, 2012). It is a substantial component of the descending pain-modulatory network and exerts an inhibitory or excitatory control on nociceptive transmission via the RVM, which in turn projects to the spinal and medullary dorsal horns (Heinricher et al., 2009).

The NCF is located in the midbrain reticular formation and has been related to the descending pain-modulating systems, acting in concert with the PAG (Dunckley et al., 2005). It is reciprocally connected with the PAG, receives input from forebrain regions including amygdala and hypothalamus, and projects to the RVM (Mantyh, 1983; Zemlan and Behbehani, 1988; Bernard et al., 1989; Hadjipavlou et al., 2006). The NCF is activated by nociceptive stimuli and has been implicated in central sensitization in fMRI studies (Dunckley et al., 2005; Zambreanu et al., 2005). The NCF was found hypofunctional in individuals experiencing migraines (Moulton et al., 2008). The NCF, like the PAG and RVM, contains functionally distinct classes of neurons that can enhance nociception ("ON cells") or inhibit nociception (“OFF cells”) (Fields et al., 1983; Heinricher et al., 1987; Haws et al., 1989).

Decreased descending inhibition or increased facilitation to the medullary dorsal horn, with increased sensitization and consequently increased nociception from dural and meningeal vascular afferents, has been suggested to be involved in the development of chronic daily headache (Okada-Ogawa et al., 2009). Consistently, patients with active $\mathrm{MOH}$ have increased pain perception and nociceptive withdrawal reflex in cephalic and extracephalic regions, which normalize after detoxification (Perrotta et al., 2010, 2012; Munksgaard et al., 2012). Possible mechanisms probably include sensitization in trigeminal ganglia and medullary dorsal horn induced by triptans or opiates (Okada-Ogawa et al., 2009; De Felice et al., 2010).

In our data, GM changes also included the DRN, a major source of widespread serotonergic projections to the forebrain (Michelsen et al., 2007). Alterations in serotonergic transmission 
A
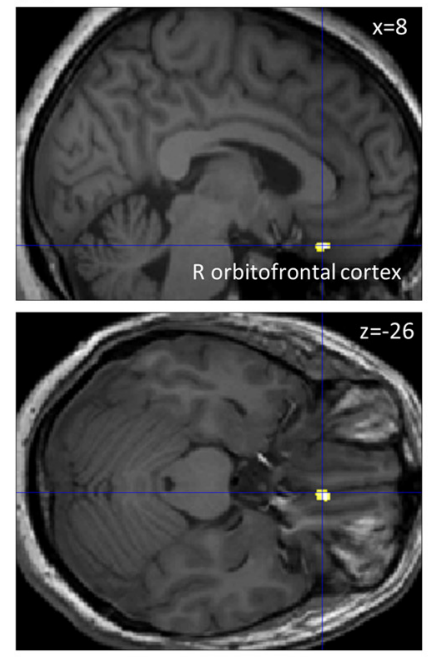
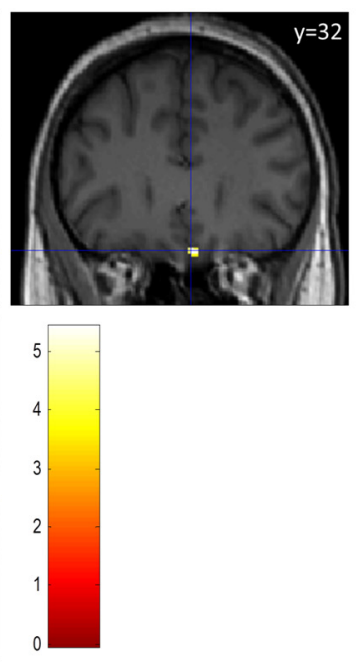

B

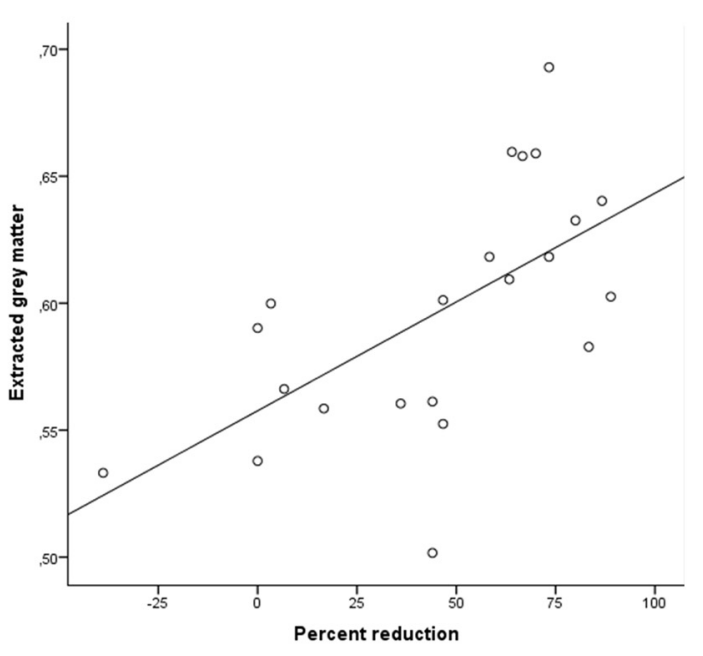

Spearman`s Rho $=0.687, p<0.001$

Figure 2. A, Responders have significantly more gray matter volume than nonresponders at baseline in the orbitofrontal cortex. Rindicates right. $\boldsymbol{B}$, Extracted gray matter in this region correlates positively with relative reduction in number of headache days per month (Spearman's $\rho=0.687, p<0.001$; i.e., more gray matter volume at baseline was associated with a greater reduction of headache days at follow-up). The $x$-axis indicates the reduction of number of days with headache per month in percentage from baseline. The $y$-axis indicates gray matter volume in arbitrary units.

have been reported in models of $\mathrm{MOH}$, including an upregulation of $5-\mathrm{HT}_{2 \mathrm{~A}}$ receptors in cortical projection areas (Supornsilpchai et al., 2010; Bongsebandhu-phubhakdi and Srikiatkhachorn, 2012). Triptans are selective $5-\mathrm{HT}_{1 \mathrm{~B} / \mathrm{D}}$ receptor agonists, binding also in the PAG, where they influence nociception, possibly via serotonergic mechanisms (Bartsch et al., 2004; Lambert, 2005). Chronic triptan administration decreased $5-\mathrm{HT}_{1 \mathrm{~B} / \mathrm{D}}$ receptor $\mathrm{mRNA}$ in the trigeminal ganglion and the basilar artery (Reuter et al., 2004), and increased the rate of 5-HT synthesis in projection areas, probably related to the downregulation of inhibitory $5-\mathrm{HT}_{1}$ autoreceptors (Dobson et al., 2004). Similarly, a downregulation of $5-\mathrm{HT}_{1 \mathrm{~B} / \mathrm{D}}$ receptors and an increased 5-HT synthesis could be assumed in the midbrain. In our data, no significant correlation between GM decrease and reduction of medication intake, or GM at baseline and medication intake was found.

Due to methodological limitations, a precise mechanism cannot be delineated since the histopathological correlates of GM changes are not yet fully understood. Whereas it seems evident that neuronal loss and gliosis is associated with GM decreases (Riederer et al., 2008), the reverse cannot be concluded, since reversible GM decreases have been observed in pain syndromes (Rodriguez-Raecke et al., 2009). Stimulus-dependent GM increases have been demonstrated in learning tasks (Draganski et al., 2004) and repetitive painful stimuli (Teutsch et al., 2008). GM changes have been related to neuronal or glial cell genesis or degeneration; increases/decreases in cell size, spine, or synapse turnover; or changes in blood flow or interstitial fluids (May, 2011), and may reflect a combination of these.

In our data, nonresponders had less GM in the right OFC at baseline, and a positive correlation between GM and treatment response was found. Formally, these patients are to be diagnosed as chronic migraine according to Headache Classification Subcommittee of the International Headache Society (2004) criteria. Metabolic and functional changes within the OFC have been previously suggested in $\mathrm{MOH}$. In a PET study, all regions that have been shown to be dysmetabolic in active $\mathrm{MOH}$ returned to normal after detoxification, except for the OFC, where hypometabolism persisted (Fumal et al., 2006). Neuropsychological studies have shown that poor performance in tasks related to OFC function in $\mathrm{MOH}$ patients predicts poor outcome after withdrawal (Gómez-Beldarrain et al., 2011). Dysfunction of OFC, particularly on the right side, has been implicated in maladaptive decision making, and dysfunction of OFC has been related to drug addiction (Tranel et al., 2002; Tanabe et al., 2009; Lucantonio et al., 2012). Patients with MOH fulfill certain criteria of substance dependence, with its severity being predictive for the outcome after detoxification (Fuh et al., 2005; Radat et al., 2008; Lundqvist et al., 2012). OFC dysfunction might thus interfere with internal control to repeated medication intake; in addition, OFC projections to the PAG may influence its pain modulation.

While there are several cross-sectional morphometric studies on headache (May, 2009), there are only few VBM studies investigating potentially reversible pain syndromes longitudinally. Obermann et al. (2009) found a GM decrease in the dorsolateral prefrontal cortex and in the anterior cingulate cortex in patients who developed chronic post-traumatic headache. In the follow-up investigation, after 12 months, when patients had become pain free, GM decreases were found to be reversible. In addition, an increase in GM was found after 12 months in the thalamus and in the midbrain, suggesting an association with antinociceptive mechanisms.

Two other studies investigated GM changes associated with osteoarthritis of the hip before and after surgery (RodriguezRaecke et al., 2009; Gwilym et al., 2010). Both studies reported reversible GM changes. The first study (Rodriguez-Raecke et al., 2009) reported GM increases in the dorsolateral prefrontal cortex, anterior cingulate cortex, and brainstem, whereas the other study (Gwilym et al., 2010) found reversible GM atrophy in the thalami. All aforementioned VBM studies reported GM increases within a time period of 4-12 months.

In our study, we did not find any GM increases in frontal, especially OFC, regions, possibly because patient samples and observation periods differed, which was against our expectations. Also, changes in GM within structures of the reward system, such as the ventral striatum, and changes in the thalamus did not reverse after detoxification. 
A limitation of this study might be that possible influences of prophylactic medication or a combination of medications cannot be ruled out entirely. However, most patients were on prophylactic medication before and after detoxification. Antidepressants and anticonvulsants seem generally not to be associated with volumetric differences, according to a recent review (Hafeman et al., 2012).

\section{Conclusions}

Our data show that response to the withdrawal of acute headache medication is associated with the decrease of previously increased GM in the midbrain. The lack of longitudinal GM changes in other regions (e.g., the ventral striatum and OFC) might underpin the idea that these patients are prone to relapse and deserve dedicated care, including multimodal treatment strategies. Future studies should investigate correlations of GM changes with behavioral measures assessing dependence and impulse control. Animal models of medication-induced sensitization should focus on midbrain structures such as the PAG and NCF.

\section{References}

Afridi SK, Giffin NJ, Kaube H, Friston KJ, Ward NS, Frackowiak RS, Goadsby PJ (2005) A positron emission tomographic study in spontaneous migraine. Arch Neurol 62:1270-1275. CrossRef Medline

Ashburner J, Friston KJ (2000) Voxel-based morphometry-the methods. Neuroimage 11:805-821. CrossRef Medline

Bartsch T, Knight YE, Goadsby PJ (2004) Activation of 5-HT(1B/1D) receptor in the periaqueductal gray inhibits nociception. Ann Neurol 56:371381. CrossRef Medline

Behbehani MM (1995) Functional characteristics of the midbrain periaqueductal gray. Prog Neurobiol 46:575-605. CrossRef Medline

Benarroch EE (2012) Periaqueductal gray: an interface for behavioral control. Neurology 78:210-217. CrossRef Medline

Bernard JF, Peschanski M, Besson JM (1989) Afferents and efferents of the rat cuneiformis nucleus: an anatomical study with reference to pain transmission. Brain Res 490:181-185. CrossRef Medline

Bezzola L, Mérillat S, Gaser C, Jäncke L (2011) Training-induced neural plasticity in golf novices. J Neurosci 31:12444-12448. CrossRef Medline

Bongsebandhu-phubhakdi S, Srikiatkhachorn A (2012) Pathophysiology of medication-overuse headache: implications from animal studies. Curr Pain Headache Rep 16:110-115. CrossRef Medline

De Felice M, Ossipov MH, Wang R, Lai J, Chichorro J, Meng I, Dodick DW, Vanderah TW, Dussor G, Porreca F (2010) Triptan-induced latent sensitization: a possible basis for medication overuse headache. Ann Neurol 67:325-337. CrossRef Medline

Dobson CF, Tohyama Y, Diksic M, Hamel E (2004) Effects of acute or chronic administration of anti-migraine drugs sumatriptan and zolmitriptan on serotonin synthesis in the rat brain. Cephalalgia 24:2-11. CrossRef Medline

Draganski B, Gaser C, Busch V, Schuierer G, Bogdahn U, May A (2004) Neuroplasticity: changes in grey matter induced by training. Nature 427: 311-312. CrossRef Medline

Dunckley P, Wise RG, Fairhurst M, Hobden P, Aziz Q, Chang L, Tracey I (2005) A comparison of visceral and somatic pain processing in the human brainstem using functional magnetic resonance imaging. J Neurosci 25:7333-7341. CrossRef Medline

Fields HL, Bry J, Hentall I, Zorman G (1983) The activity of neurons in the rostral medulla of the rat during withdrawal from noxious heat. J Neurosci 3:2545-2552. Medline

Fuh JL, Wang SJ, Lu SR, Juang KD (2005) Does medication overuse headache represent a behavior of dependence? Pain 119:49-55. CrossRef Medline

Fumal A, Laureys S, Di Clemente L, Boly M, Bohotin V, Vandenheede M, Coppola G, Salmon E, Kupers R, Schoenen J (2006) Orbitofrontal cortex involvement in chronic analgesic-overuse headache evolving from episodic migraine. Brain 129:543-550. CrossRef Medline

Goadsby PJ (2002) Neurovascular headache and a midbrain vascular malformation: evidence for a role of the brainstem in chronic migraine. Cephalalgia 22:107-111. CrossRef Medline
Gómez-Beldarrain M, Carrasco M, Bilbao A, García-Moncó JC (2011) Orbitofrontal dysfunction predicts poor prognosis in chronic migraine with medication overuse. J Headache Pain 12:459-466. CrossRef Medline

Gwilym SE, Filippini N, Douaud G, Carr AJ, Tracey I (2010) Thalamic atrophy associated with painful osteoarthritis of the hip is reversible after arthroplasty: a longitudinal voxel-based morphometric study. Arthritis Rheum 62:2930-2940. CrossRef Medline

Haas DC, Kent PF, Friedman DI (1993) Headache caused by a single lesion of multiple sclerosis in the periaqueductal gray area. Headache 33 : 452-455. CrossRef Medline

Hadjipavlou G, Dunckley P, Behrens TE, Tracey I (2006) Determining anatomical connectivities between cortical and brainstem pain processing regions in humans: a diffusion tensor imaging study in healthy controls. Pain 123:169-178. CrossRef Medline

Hafeman DM, Chang KD, Garrett AS, Sanders EM, Phillips ML (2012) Effects of medication on neuroimaging findings in bipolar disorder: an updated review. Bipolar Disord 14:375-410. CrossRef Medline

Haws CM, Williamson AM, Fields HL (1989) Putative nociceptive modulatory neurons in the dorsolateral pontomesencephalic reticular formation. Brain Res 483:272-282. CrossRef Medline

Headache Classification Subcommittee of the International Headache Society (2004) The international classification of headache disorders, Ed 2. Cephalalgia 24 [Suppl 1]:9-160. CrossRef Medline

Heinricher MM, Cheng ZF, Fields HL (1987) Evidence for two classes of nociceptive modulating neurons in the periaqueductal gray. J Neurosci 7:271-278. Medline

Heinricher MM, Tavares I, Leith JL, Lumb BM (2009) Descending control of nociception: specificity, recruitment and plasticity. Brain Res Rev 60: 214-225. CrossRef Medline

Lambert GA (2005) Preclinical neuropharmacology of naratriptan. CNS Drug Rev 11:289-316. Medline

Lucantonio F, Stalnaker TA, Shaham Y, Niv Y, Schoenbaum G (2012) The impact of orbitofrontal dysfunction on cocaine addiction. Nat Neurosci 15:358-366. CrossRef Medline

Lundqvist C, Grande RB, Aaseth K, Russell MB (2012) Dependence scores predict prognosis of medication overuse headache: a prospective cohort from the Akershus study of chronic headache. Pain 153:682-686. CrossRef Medline

Mantyh PW (1983) Connections of midbrain periaqueductal gray in the monkey. II. Descending efferent projections. J Neurophysiol 49:582-594. Medline

May A (2009) Morphing voxels: the hype around structural imaging of headache patients. Brain 132:1419-1425. CrossRef Medline

May A (2011) Experience-dependent structural plasticity in the adult human brain. Trends Cogn Sci 15:475-482. CrossRef Medline

Michelsen KA, Schmitz C, Steinbusch HW (2007) The dorsal raphe nucleus-from silver stainings to a role in depression. Brain Res Rev 55:329-342. CrossRef Medline

Moulton EA, Burstein R, Tully S, Hargreaves R, Becerra L, Borsook D (2008) Interictal dysfunction of a brainstem descending modulatory center in migraine patients. PLoS One 3:e3799. CrossRef Medline

Munksgaard SK, Bendtsen L, Jensen RH (2012) Medication overuse headache: sensitization is reduced after withdrawal. Paper presented at Third European Headache and Migraine Trust International Congress, London, UK, September.

Naidich TP, Duvernoy HM, Delman BN, Sorensen AG, Kollias SS, Haacke EM (2009) Internal architecture of the brainstem with key axial sections. In: Duvernoy's atlas of the human brain stem and cerebellum, pp 84-87. New York: Springer.

Obermann M, Nebel K, Schumann C, Holle D, Gizewski ER, Maschke M, Goadsby PJ, Diener HC, Katsarava Z (2009) Gray matter changes related to chronic posttraumatic headache. Neurology 73:978-983. CrossRef Medline

Okada-Ogawa A, Porreca F, Meng ID (2009) Sustained morphine-induced sensitization and loss of diffuse noxious inhibitory controls in durasensitive medullary dorsal horn neurons. J Neurosci 29:15828-15835. CrossRef Medline

Olesen J, Bousser MG, Diener HC, Dodick D, First M, Goadsby PJ, Göbel H, Lainez MJ, Lance JW, Lipton RB, Nappi G, Sakai F, Schoenen J, Silberstein SD, Steiner TJ (2006) New appendix criteria open for a broader concept of chronic migraine. Cephalalgia 26:742-746. CrossRef Medline

Perrotta A, Serrao M, Sandrini G, Burstein R, Sances G, Rossi P, Bartolo M, 
Pierelli F, Nappi G (2010) Sensitisation of spinal cord pain processing in medication overuse headache involves supraspinal pain control. Cephalalgia 30:272-284. CrossRef Medline

Perrotta A, Arce-Leal N, Tassorelli C, Gasperi V, Sances G, Blandini F, Serrao M, Bolla M, Pierelli F, Nappi G, Maccarrone M, Sandrini G (2012) Acute reduction of anandamide-hydrolase (FAAH) activity is coupled with a reduction of nociceptive pathways facilitation in medicationoveruse headache subjects after withdrawal treatment. Headache 52: 1350-1361. CrossRef Medline

Pietrobon D, Striessnig J (2003) Neurobiology of migraine. Nat Rev Neurosci 4:386-398. CrossRef Medline

Radat F, Creac'h C, Guegan-Massardier E, Mick G, Guy N, Fabre N, Giraud P, Nachit-Ouinekh F, Lantéri-Minet M (2008) Behavioral dependence in patients with medication overuse headache: a cross-sectional study in consulting patients using the DSM-IV criteria. Headache 48:1026-1036. CrossRef Medline

Raskin NH, Hosobuchi Y, Lamb S (1987) Headache may arise from perturbation of brain. Headache 27:416-420. CrossRef Medline

Reuter U, Salomone S, Ickenstein GW, Waeber C (2004) Effects of chronic sumatriptan and zolmitriptan treatment on 5-HT receptor expression and function in rats. Cephalalgia 24:398-407. CrossRef Medline

Riederer F, Lanzenberger R, Kaya M, Prayer D, Serles W, Baumgartner C (2008) Network atrophy in temporal lobe epilepsy: a voxel-based morphometry study. Neurology 71:419-425. CrossRef Medline

Riederer F, Marti M, Luechinger R, Lanzenberger R, von Meyenburg J, Gantenbein AR, Pirrotta R, Gaul C, Kollias S, Sándor PS (2012) Grey matter changes associated with medication-overuse headache: correlations with disease related disability and anxiety. World J Biol Psychiatry 13:517-525. CrossRef Medline

Riederer F, Gantenbein AR, Marti M, Luechinger R, Kollias S, Sándor PS (2013) Grey matter changes in medication-overuse headache before and after medication withdrawal. J Headache Pain 14 [Suppl 1]:P177. CrossRef

Rocca MA, Ceccarelli A, Falini A, Colombo B, Tortorella P, Bernasconi L, Comi G, Scotti G, Filippi M (2006) Brain gray matter changes in migraine patients with T2-visible lesions: a 3-T MRI study. Stroke 37: 1765-1770. CrossRef Medline

Rodriguez-Raecke R, Niemeier A, Ihle K, Ruether W, May A (2009) Brain gray matter decrease in chronic pain is the consequence and not the cause of pain. J Neurosci 29:13746-13750. CrossRef Medline

Supornsilpchai W, le Grand SM, Srikiatkhachorn A (2010) Involvement of pro-nociceptive 5-HT2A receptor in the pathogenesis of medicationoveruse headache. Headache 50:185-197. CrossRef Medline

Tanabe J, Tregellas JR, Dalwani M, Thompson L, Owens E, Crowley T, Banich M (2009) Medial orbitofrontal cortex gray matter is reduced in abstinent substance-dependent individuals. Biol Psychiatry 65:160-164. CrossRef Medline

Teutsch S, Herken W, Bingel U, Schoell E, May A (2008) Changes in brain gray matter due to repetitive painful stimulation. Neuroimage 42:845-849. CrossRef Medline

Tranel D, Bechara A, Denburg NL (2002) Asymmetric functional roles of right and left ventromedial prefrontal cortices in social conduct, decisionmaking, and emotional processing. Cortex 38:589-612. CrossRef Medline

Veloso F, Kumar K, Toth C (1998) Headache secondary to deep brain implantation. Headache 38:507-515. CrossRef Medline

Weiller C, May A, Limmroth V, Jüptner M, Kaube H, Schayck RV, Coenen HH, Diener HC (1995) Brain stem activation in spontaneous human migraine attacks. Nat Med 1:658-660. CrossRef Medline

Welch KM, Nagesh V, Aurora SK, Gelman N (2001) Periaqueductal gray matter dysfunction in migraine: cause or the burden of illness? Headache 41:629-637. CrossRef Medline

Whitwell JL (2009) Voxel-based morphometry: an automated technique for assessing structural changes in the brain. J Neurosci 29:9661-9664. CrossRef Medline

Zambreanu L, Wise RG, Brooks JC, Iannetti GD, Tracey I (2005) A role for the brainstem in central sensitisation in humans. Evidence from functional magnetic resonance imaging. Pain 114:397-407. CrossRef Medline

Zemlan FP, Behbehani MM (1988) Nucleus cuneiformis and pain modulation: anatomy and behavioral pharmacology. Brain Res 453:89-102. CrossRef Medline 